\title{
KINETICS OF P - NITROPHENYL ACETATE HYDROLYSIS CATALYZED BY $\alpha$ - CHYMOTRYPSIN IN PRESENCE OF POLYETHYLENE GLYCOL
}

\author{
ELSA ABUIN ${ }^{(*)}$, EDUARDO LISSI AND RAQUEL BRIDI \\ Facultad de Química y Biología, Universidad de Santiago de Chile, \\ Av. Bernardo O'Higgins 3363, Santiago, Chile \\ (Received: July 25, 2011 - Accepted: November 7, 2011)
}

\begin{abstract}
The effect of poly (ethyleneglycol) (PEG) addition on the rate of p-nitrophenyl acetate (PNPA) catalyzed by a- chymotrypsin has been measured in TRIS buffer at $\mathrm{pH}=7.4$. The presence of PEG (up to $30 \% \mathrm{p} / \mathrm{v}$ ) leads to an increase in the rate of the process. The effect of PEG is evident both, in the pre-steady state and steady state stages of the process. The reaction follows a Michaelis-Menten mechanism under all the conditions employed. The Michaelis constant slightly decreases and the catalytic rate constant slightly increases with PEG concentration over all the polymer concentration range employed (up to $30 \%$ ). The decrease in the Michaelis constant suggests that the effect of the polymer is due to crowding.
\end{abstract}

\section{INTRODUCTION}

Studies of enzymes activity are traditionally carried out in dilute solutions, typically at protein concentrations approximately $1 \mathrm{mg} / \mathrm{mL}$. Such an environment is different from that in which enzymes perform their biological function. In fact, biological media may be diluted in the enzyme of interest, but contains a large variety of other macromolecules. The presence of these macromolecules can affect the activity of enzymes mainly through three factors, namely, adsorption of the substrate onto the protein, direct non covalent interaction between the enzyme and the added inert macromolecule, and the so called "crowding effect". The last effect (also called "space filling effect" or "excluded volume effect") could alter the enzyme conformation leading to changes in its catalytic activity. To simulate a more physiological environment in which to study enzyme kinetics, neutral polymers such as dextrans, polysaccharides or poly (ethylene glycol), Carbopol or biomacromolecules are frequently added to the reaction medium. ${ }^{1-13}$ The effect provoked by crowding on the enzyme performance is dependent on the particular enzyme - crowding agent couple. Some relevant works are summarized below.

Bergman and Winzor ${ }^{12}$ studied the effect of albumin on the reduction of pyruvate by rabbit muscle lactate dehydrogenase. They found that in the presence of albumin the catalysis was enhanced as a consequence of an increase in the catalytic rate constant, with no appreciable effect on the Michaelis constant of pyruvate or its co-factor. These authors explained the results in terms of a "crowding effect" which provokes a change in the conformation of the enzyme. Olsen ${ }^{13}$ studied the kinetic properties of hexokinase in concentrated solutions of bovine serum albumin, (up to ca. $4 \mathrm{mM}$ ). All results could be accounted for by a Michaelis-Menten's formalism, and both $\mathrm{K}_{\mathrm{M}}$ and $\mathrm{k}_{\text {cat }}$ decreased with increasing protein concentration. The decrease in $\mathrm{K}_{\mathrm{M}}$ with increasing protein concentration was ascribed to an increase in the ratio of activity coefficients between the native enzyme and the enzyme-substrate complex. The decrease in $\mathrm{k}_{\text {at }}$ with increasing protein concentration was also explained in terms of the "crowding effect" which, in this case leads to conformational changes of the enzyme that disfavor the catalytic step. Derham and Harding ${ }^{11}$ reported that the addition of Dextran (10-60 \% p/v), PEG (10$60 \% \mathrm{p} / \mathrm{v})$ or Carbopol $(0,025-0.25 \% \mathrm{p} / \mathrm{v})$ decreases the activity of urease; for Dextran, the decrease in activity was found to be larger when the molecular weight of the polymer is higher. In these systems, the decrease in activity was explained in terms of a viscosity effect that turns the reaction slower due to the restricted difussion of the reagents. No discussion regarding the effect of the polymers upon the kinetic parameters is afforded.

Recently, we have reported on the effect of human serum albumin (HSA) addition on the rate of hydrolysis of N-glutaryl-L-phenylalanine p-nitroanilide (GPNA) catalyzed by $\alpha$-chymotrypsin..$^{14}$ The presence of HSA (up to $200 \mu \mathrm{M}$ ) leads to a decrease in the rate of the process. In this system, GPNA binds to HSA and, after correction of the kinetic data taking into account this binding, the activity of the enzyme, and the derived Michaelis constant and catalytic rate constant remain almost independent of the presence of albumin, indicating that the depletion of the substrate due to its binding to HSA is the main factor affecting the enzyme activity. Asaad and Engberts ${ }^{15}$ studied the kinetics of the trypsin-catalyzed hydrolysis of p-nitrophenyl acetate upon addition of polyethylene glycol. They found that the Michaelis constant remains almost unchanged, while the added PEG cause a moderate decrease in $\mathrm{k}_{\text {cat }}$ from 3.85 $10^{-3} \mathrm{~s}^{-1}$ to $1.4410^{-3} \mathrm{~s}^{-1}$ over the PEG concentration range studied (up to $395 \mathrm{~g}$ $\left.\mathrm{L}^{-1} ; \mathrm{M}_{w}=8000\right)$.

Given the large number of factors that can be relevant under crowding conditions (reduced rate of diffusion controled steps, protein-enzyme association, increased local concentrations, preferential solvation, conformational changes in the enzyme) it is difficult to predict the polymer effect and to establish the origin of the dependence, since each enzymepolymer system can show a different behavior.

In the present work we report the results obtained in the study of the effect of polyethylene glycol (PEG) addition upon the kinetics of hydrolysis of p-nitrophenyl acetate (PNPA) catalyzed by $\alpha$-chymotrypsin $(\alpha-\mathrm{CT})$.

\section{EXPERIMENTAL SECTION}

\subsection{Reagents and equipments}

$\alpha$-Chymotrypsin, ( $\alpha$-CT, Type II, from bovine pancreas), poly (ethylene glycol, PEG (nominal molecular weight 3 500) and p-nitrophenyl acetate (PNPA) from Sigma were used as received. Ultrapure water obtained from a Modulab Type II equipment was employed to prepare all the solutions. Tris-(hydroxymethyl) aminomethane (TRIS) was a product from Aldrich. All measurements were performed at $25 \pm 1{ }^{\circ} \mathrm{C}$, in TRIS buffer $(\mathrm{pH}=7.0)$ Absorption spectra and absorbances were recorded in a Hewlett-Packard UVvisible 8453 spectrometer.

\subsection{Reaction rate measurements}

The rate of PNPA hydrolysis, catalyzed by $\alpha$-CT, was measured at $25^{\circ} \mathrm{C}$ in aqueous buffered solution and in PEG (up to $30 \%(\mathrm{p} / \mathrm{v})$ solutions at $\mathrm{pH}=7.0$ (10 mM TRIS-HCL buffer). The nominal molecular weight of PEG employed was $3500 \mathrm{Da}$. The process was followed by registering at $400 \mathrm{~nm}(\varepsilon=17700$ $\mathrm{M}^{-1} \mathrm{~cm}^{-1}$ ) the absorbance of $p$-nitrophenol PNP released during the reaction as a function of time. The extinction coefficient of PNP was independent of PEG concentration in the concentration range considered in the present work. The reaction was initiated by addition of an aliquot of a concentrated $\alpha$-CT solution to $3 \mathrm{~mL}$ of the solution containing a given concentration of PNPA in buffer (or the PNPA + PEG solution) as to obtain a final enzyme concentration equal to $10 \mathrm{mM}$. PNP versus time plots were downcurved during the first $10-50$ seconds (depending on the PEG concentration) of reaction. Rate values reported, V, corresponds to those obtained after a lineal PNP concentrations versus time dependence was attained.

\section{RESULTS AND DISCUSSION}

The catalysis of the hydrolysis of esters by $\alpha$-CT is represented by the following steps. ${ }^{16-19}$

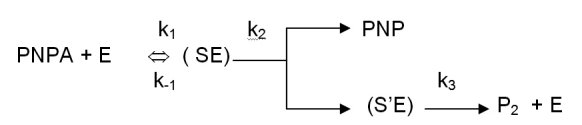


where $\mathrm{E}$ is the free enzyme, (SE) is the enzyme-substrate complex, (S'E) is the acidic product enzyme intermediate and $\mathrm{PNP}$ and $\mathrm{P}_{2}$ are the basic and the acidic products, respectively.

Figure 1 shows typical plots of the time course of PNP formation in the hydrolysis of PNPA catalyzed by $\alpha$-CT. The data show a fast intial rate that readily decays to a steady state situation. The transient phase is associated with the time required to reach the steady state concentration for the (S'E) intermediate, and it is also present in the presence of PEG. The data of this work do not permit a detailed analysis of this dependence, but suggest that the steady state condition is reached faster in absence of the polymer; with this aim, it is planned to study the effect of the presence of the polymer on the fast component employing p-nitrophenyl trimethylacetate as substrate, since for this compound the lag time is very large, ${ }^{20}$ so facilitating the kinetic measurements.

Typical results obtained for the dependence of the rate of the process under steady state conditions (ie., rates obtained after a linear PNP concentrations versus time dependence was attained) with PEG concentration are shown in Figure 2.

By applying a steady sate treatment to the intermediates in Eq. (1) it can be demonstrated that the steady sate rate for the reaction, V, is given by Eq. (2),

\section{$\mathrm{V}=\{(\mathrm{k} 2 \mathrm{k} 3 / \mathrm{k} 2+\mathrm{k} 3)[\alpha-\mathrm{CT}] 0[\mathrm{PNPA}]\} /\{[\mathrm{PNPA}]+(\mathrm{Ks} . \mathrm{k} 3 / \mathrm{k} 2+\mathrm{k} 3)\}$}

implying a Michaelis-Menten kinetics, with:

and

$$
\begin{aligned}
& \mathrm{K}_{\mathrm{M}}=\mathrm{k}_{-1} / \mathrm{k}_{1}\left[\mathrm{k}_{3} /\left(\mathrm{k}_{2}+\mathrm{k}_{3}\right)\right] \\
& \mathrm{k}_{\text {cat }}=\mathrm{k}_{2} \mathrm{k}_{3} /\left(\mathrm{k}_{2}+\mathrm{k}_{3}\right)
\end{aligned}
$$

The data of Figure 2 show that addition of PEG increases the rate of the process over all the substrate concentration range. From the fitting of the data to the Michaleis-Menten equation the values of $\mathrm{k}_{\text {and }} \mathrm{K}_{\mathrm{M}}$ were derived; they are shown Figure 3 and 4, respectively. It is seen that $\mathrm{k}_{\text {cat }}$ increases and $\mathrm{K}_{\mathrm{M}}$ decreases in the presence of the polymer. The effect on $\mathrm{K}_{\mathrm{M}}$ is contrary to that expected if the substrate were associated with the polymer. ${ }^{14}$ Hence, both, the increase in $\mathrm{k}_{\mathrm{pan}}$ and the decrease in $\mathrm{K}_{\mathrm{m}}$ must be associated with conformational changes experienced by the enzyme due the crowding of the media. In fact, it can be estimated that about $26 \%$ of the volume is occupied by PEG at the highest concentration employed $(30 \% \mathrm{p} / \mathrm{v}) \cdot{ }^{21}$ Similarly, the mean distance between the border of PEG molecules at this concentration can be estimated as ca $4.6 \mathrm{~nm}$, a distance is similar to the diameter of the enzyme $(4-5 \mathrm{~nm})$.

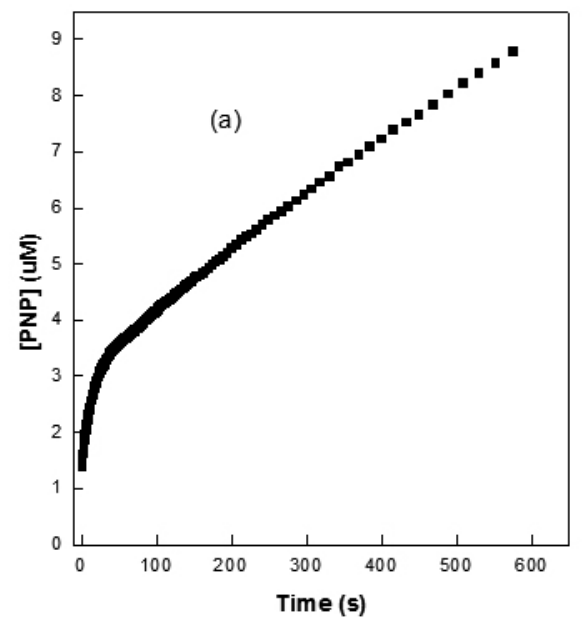

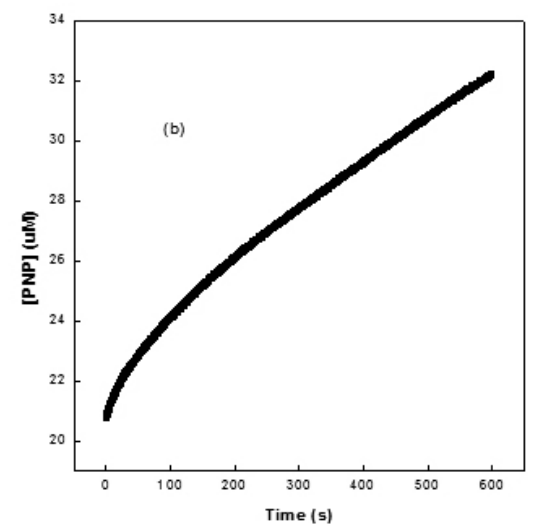

Figure 1: Time course of PNP formation in the hydrolysis of PNPA catalyzed by $\alpha$-CT. (a) in the absence of PEG; (b) $[\mathrm{PEG}]=30 \%(\mathrm{p} / \mathrm{v})$; [PNPA] $=0.05 \mathrm{mM}$

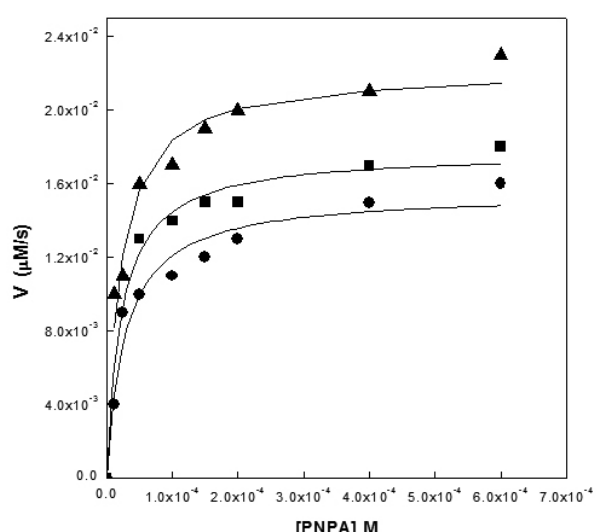

Figure 2: Effect of PEG concentration on the relationship between the reaction rate $\mathrm{V}$, and the concentration of PNPA. (-) In the absence of PEG; (घ) $[\mathrm{PEG}]=10 \%(\mathrm{p} / \mathrm{v}) ;(\boldsymbol{\Delta})[\mathrm{PEG}]=30 \%(\mathrm{p} / \mathrm{v})$. The lines correspond to the fitting of the data to the Michaelis-Menten equation

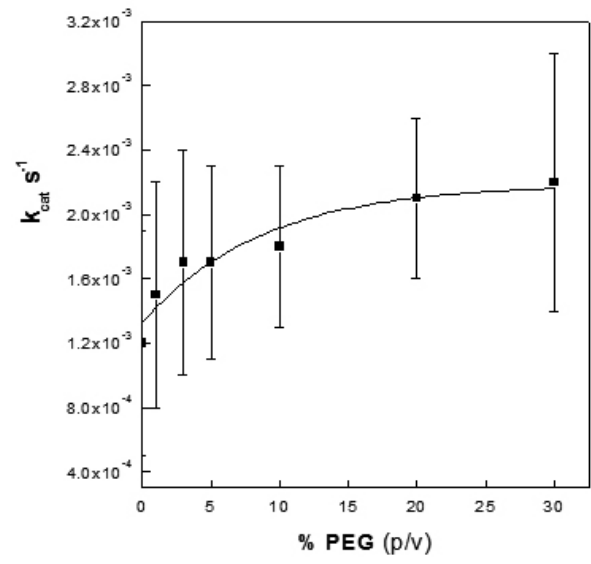

Figure 3: Dependence of $\mathrm{k}_{\text {cat }}$ with the percentage of PEG 


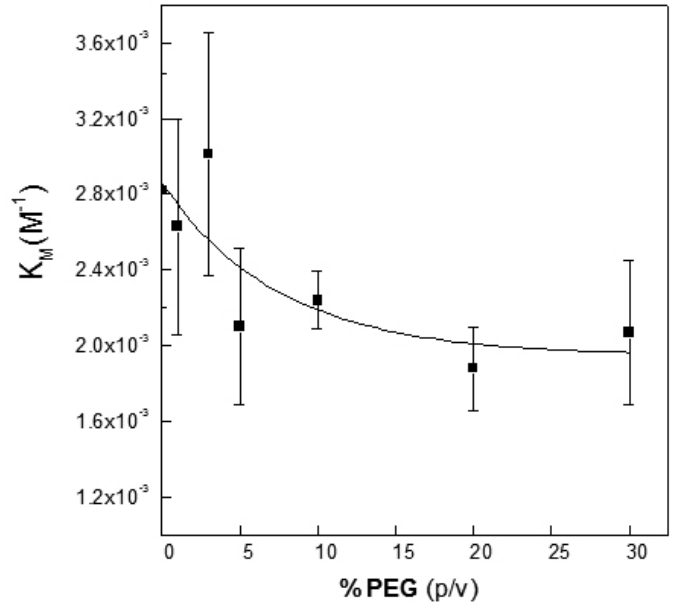

Figure 4: Dependence of $K_{M}$ with the percentage of PEG

Given the relatively small modification of the kinetic parameters in such a highly crowded medium, it is possible to speculate that the conformational change imposed on the enzyme by the presence of the polymer would take place without a significant modification of the structure of the neighborhood of the enzyme active site. In fact, the change in $\mathrm{K}_{\mathrm{M}}$ can be adscribed to a increase in the local concentration of the substrate due to the smaller volume available. The same conclusion was reached by Asaad and Engberts ${ }^{15}$ for the case of addition of high concentrations of PEG in the hydrolysis of PNPA catalyzed by trypsin.

\section{ACKNOWLEDGMENTS}

Thanks are given to Fondecyt (Grant \# 1095036) and Dicyt (USACH) for financial support.

\section{REFERENCES}

1. B. van der Berg, R. J. Ellis, C.M. Dobson (1999) The EMBO J. 18, 6927 (1999).

2. I. Pastor, E. Vilaseca, S. Madurga, J. L. Garcés, M. Cascante, F.Mas, J. Phys. Chem. B 115, 1115 (2011).

3. A.P Minton, J. Wilf, Biochemistry 20, 4821 (1981).

4. K. Totani, Y. Ihara, I. Matsuo, Y. Ito, J. Am. Chem. Soc. 130, 2107 (2008).

5. Y. Sasaki, D. Miyoshi, N. Sugimoto, Biotech. J. 1, 440 (2006).

6. N. A. Chebotareva, Biochemistry 72, 1478 (2007).

7. I. Pozdnyakova, P. Wittung-Stashede, Biochim. Biophys. Acta 1804,740 (2010).

8. L. Homchaudhuri, N. Sarma, R. Swaminathan, Biopolymers 83, 477 (2006).

9. J. Li, S. Zhang, Chi- chen Wang, J. Biol. Chem. 276, 34396 (2001).

10. T. G.A. Lonhienne, D. J. Winzor, Biochemistry 41,6897 (2002).

11. B. K. Derham, J. J. Harding, Biochim. Biophys. Acta 1764, 1000 (2006)

12. D. A. Bergman, D. J. Winzor, Eur. J. Biochem., 185, 91 (1989)

13. S. N. Olsen, Thermochimica Acta 448, 12 (2006)

14. E. Abuin, E. Lissi, M. Ahumada, Protein J., 30, 143 (2011)

15. N. Asaad, J. B. F. N. Engberts, J. Am. Chem. Soc., 15, 6874 (2003)

16. E. A. Belysaeva, D. V. DV, N.L. Eremeev, Biochemistry (Moscow) 67, $1032(2002)$

17. M. L. Bender, F. J. Kézdy, F. C. Wedler, J. Chem. Ed. 44, 84 (1967)

18. M. Blocher, P. Walde, I. J. Dunn, Biotechnol. Bioeng. 62, 36 (1999).

19. E. Abuin, E. Lissi, R. Duarte, J. Molec. Cat. B: Enzymatic, 31, 83 (2004)

20. C. E. McDonald, A. K. Balls, J. Biol. Chem., 227,727 (1957)

21. A. Eliassi, H. Modarress, J. Chem. Eng. Data 43, 719 (1998) 